\title{
Optical Properties of Hydrated Tungsten Trioxide 3WO3-H2O
}

\author{
Iryna Valyukh, Z. Jiao, Hans Arwin and X. W. Sun
}

\section{Linköping University Post Print}

\section{Tweet}

N.B.: When citing this work, cite the original article.

Original Publication:

Iryna Valyukh, Z. Jiao, Hans Arwin and X. W. Sun, Optical Properties of Hydrated Tungsten Trioxide 3WO3-H2O 2014, Thin Solid Films.

http://dx.doi.org/10.1016/j.tsf.2014.04.049

Copyright: Elsevier

http://www.elsevier.com/

Postprint available at: Linköping University Electronic Press

http://urn.kb.se/resolve?urn=urn:nbn:se:liu:diva-106422 


\title{
Optical properties of hydrated tungsten trioxide $3 \mathrm{WO}_{3} \cdot \mathrm{H}_{2} \mathrm{O}$
}

\author{
I. Valyukh ${ }^{\mathrm{a}}$, Z. Jiao ${ }^{\mathrm{b}}, \mathrm{H}$. Arwin ${ }^{\mathrm{a}}$, X.W. Sun ${ }^{\mathrm{b}}$ \\ a Laboratory of Applied Optics, Department of Physics, Chemistry and Biology, Linköping University, SE-58183 Linköping, Sweden \\ b School of Electrical and Electronic Engineering, Nanyang Technological University, Nanyang Avenue, Singapore 639798, Singapore
}

\section{A R T I C L E I N F O}

Available online $\mathrm{xxxx}$

Keywords:

Ellipsometry

Dielectric function

Hydrated tungsten trioxide

\begin{abstract}
A B S T R A C T
Spectroscopic ellipsometry was used to determine the optical properties of plate-like hydrated tungsten trioxide $\left(3 \mathrm{WO}_{3} \cdot \mathrm{H}_{2} \mathrm{O}\right.$ ) films in the energy range $300-4000 \mathrm{~cm}^{-1}$. Films with different thicknesses were deposited on glass substrates pre-coated with fluorine-doped tin oxide via an efficient and simple hydrothermal method. Paramet-

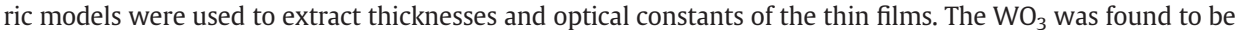
more hydrated for thicker films. Moreover, the nano-plates are larger in thicker films, which leads to a decrease of the transmission due to an increase of the scattering. Features in the obtained dielectric functions of the $3 \mathrm{WO}_{3} \cdot \mathrm{H}_{2} \mathrm{O}$ thin films were compared with the earlier published optical spectra of $\mathrm{WO}_{3}$ and its hydrates $1 / 2 \mathrm{WO}_{3} \cdot \mathrm{H}_{2} \mathrm{O}$ and $\mathrm{WO}_{3} \cdot \mathrm{H}_{2} \mathrm{O}$.
\end{abstract}

(C) 2014 Elsevier B.V. All rights reserved.

\section{Introduction}

Tungsten oxide hydrates are widely used materials for production of carbides, hard metals, power batteries and electronic materials. Moreover, they can exhibit unique electrochromic properties that make them attractive to use in energy efficient smart windows [1]. There are many crystalline hydrated tungsten trioxide compounds having the general formula $n \mathrm{WO}_{3} \mathrm{H}_{2} \mathrm{O}$. Due to the wide application in modern technology, their properties are studied intensively and results have been reported for $n \mathrm{WO}_{3} \mathrm{H}_{2} \mathrm{O}$ compounds with $n=0.5,1,1.25,2$ and 3 [2-8]. Efficiency of electrochromic (EC) thin-film devices depends on the thicknesses of EC materials [9] as well as on their structure, optical properties and chemical purity.

Infrared (IR) spectroscopic ellipsometry is a useful technique for characterization of nanostructured $3 \mathrm{WO}_{3} \mathrm{H}_{2} \mathrm{O}$ films, because film thickness and dielectric function of nano-materials can be determined simultaneously. Moreover, in comparison with measurements of IR transmission spectra, deposition on IR-transparent substrates is not required for ellipsometry. Films deposited on conductors which are transparent in the visible range but opaque in IR, as used in EC devices, can therefore be studied.

In our previous work we have used X-ray diffraction, X-ray photoelectron spectroscopy, transmission electron microscopy, scaning electron microscopy (SEM) and Raman spectroscopy $[5,6]$ to investigate the structure of $3 \mathrm{WO}_{3} \cdot \mathrm{H}_{2} \mathrm{O}$ films deposited directly on glass substrates pre-coated with fluorine-doped tin oxide (FTO). We have indicated that the $3 \mathrm{WO}_{3} \cdot \mathrm{H}_{2} \mathrm{O}$ lattice is formed by stacked layers that consist of the two types of corner-sharing $\mathrm{WO}_{6}$ octahedrons in an orthorhombic phase. The first type is similar to the structural features of tungsten trioxide $\left(\mathrm{WO}_{3}\right)$ and consists of a central atom surrounded by six oxygen atoms. In the second type two of the oxygen atoms are replaced by a shorter terminal $\mathrm{W}=\mathrm{O}$ bond and a longer $\mathrm{W}-(\mathrm{OH})_{2}$ bond, respectively [5].

In this work, we have investigated plate-like orthorhombic $3 \mathrm{WO}_{3} \cdot \mathrm{H}_{2} \mathrm{O}$ films deposited on FTO pre-coated glass substrates using IR spectroscopic ellipsometry that also can detect amorphous compounds which are hard to analyze with X-ray methods. Features in the optical spectra of the $3 \mathrm{WO}_{3} \cdot \mathrm{H}_{2} \mathrm{O}$ films of different thicknesses were compared with previous data on $\mathrm{WO}_{3}$ and its hydrates $\mathrm{WO}_{3} \cdot \mathrm{H}_{2} \mathrm{O}$ and $1 / 2 \mathrm{WO}_{3} \cdot \mathrm{H}_{2} \mathrm{O}$.

\section{Experimental details}

\subsection{Sample preparation}

A detailed description of the hydrothermal deposition of $3 \mathrm{WO}_{3} \cdot \mathrm{H}_{2} \mathrm{O}$ films on the FTO-glass substrates is not a scope of this paper and can be found elsewhere $[5,6]$. A schematic illustration of the formation process for $3 \mathrm{WO}_{3} \cdot \mathrm{H}_{2} \mathrm{O}$ films is shown in Fig. 1 [5].

\subsection{Acquisition and analysis of ellipsometry data}

A rotating analyzer ellipsometer (VASE, J.A. Woollam Co., Inc.) has been used for measuring transmittance in the range of 250-2000 nm. The ellipsometric angles $\Psi$ and $\Delta$ defined by the ellipsometric ratio [10] ${ }^{R_{p}} / R_{S}=\tan \Psi \exp (i \Delta)$, where $R_{p}$ and $R_{S}$ are reflection coefficients for the light components parallel (subscript $p$ ) and perpendicular (subscript $s$ ) to the plane of incidence, respectively, were measured with an infrared Fourier transform rotating compensator ellipsometer (J.A. Woollam Co., Inc.). Measurements were performed in reflection mode at angles of incidence from 50 to $70^{\circ}$ in the spectral range of $300-4000 \mathrm{~cm}^{-1}$ with a resolution of $4 \mathrm{~cm}^{-1}$. The dielectric function 


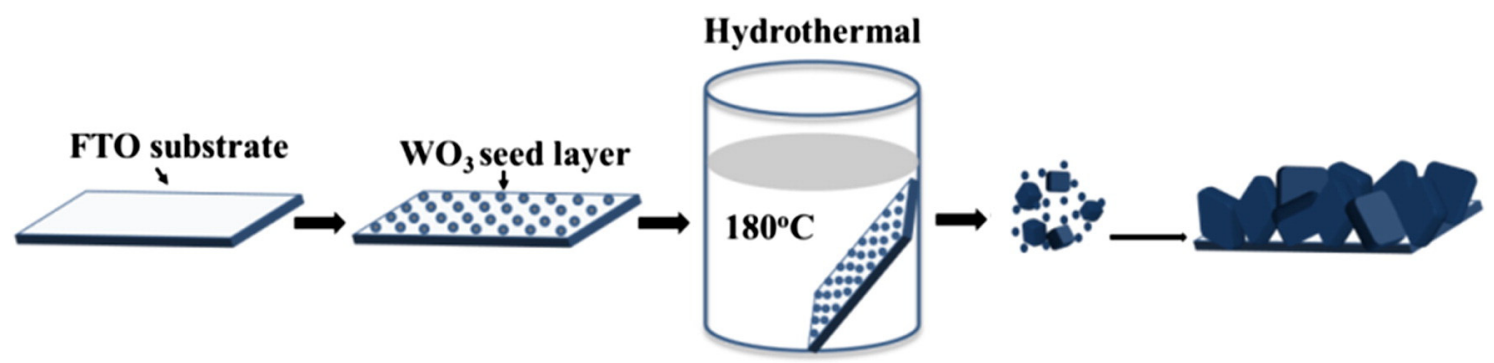

Fig. 1. Schematic illustration of $3 \mathrm{WO}_{3} \cdot \mathrm{H}_{2} \mathrm{O}$ film growth [5].

$\varepsilon=\varepsilon_{1}+i \varepsilon_{2}$ of the material as well as film thickness was extracted by using a parametric model for the $3 \mathrm{WO}_{3} \cdot \mathrm{H}_{2} \mathrm{O}$ film [11].

The structural model consists of an FTO layer - a $3 \mathrm{WO}_{3} \cdot \mathrm{H}_{2} \mathrm{O}$ film air. The FTO-glass substrate was represented by a semi-infinite FTO layer due to its high conductivity and large thickness (400 nm [5]). The dielectric function of FTO layer was represented by a set of Lorentz $(L)$ and Gauss $(G)$ oscillators $[10,11]$ that are Kramers-Kronig (KK) consistent. The model dielectric function used is:

$\varepsilon=\varepsilon_{\infty}+\sum_{j} \varepsilon_{L j}+\sum_{i} \varepsilon_{G i}$

where $\varepsilon_{\infty}$ is the high-frequency contribution. The found optical properties of the FTO substrate were then used in the further analysis. The hydrated $\mathrm{WO}_{3}$ thin films were represented by a uniform layer with a dielectric function of the type shown in Eq. (1).

The obtained parametric models provide a connection between measured data and physical parameters of interest. The parameter values are not unique since correlation between fitted parameters was observed. However, we are interested in the shape of the dielectric function only. Therefore, the so-called point-by-point (pbp) fits were performed at fixed thicknesses of layers. The thicknesses were determined using parametric models. In the case of pbp fitting, the dielectric functions of interest were extracted from the experimental data at each wavelength and are independent of all other data points, i.e. the pbp fit does not yield KK-consistent results. The results determined using Eq. (1), on the other hand, are KK consistent. Thus it is important to do both. The advantage of a pbp fitting is that all features in the optical spectra are preserved, although the influence of the noise can be seen.

\section{Results and discussions}

Transmission spectra of an FTO-glass substrate and $3 \mathrm{WO}_{3} \cdot \mathrm{H}_{2} \mathrm{O}$ films are shown in Fig. 2. It is seen from Fig. 2 that the transmission depends on film thickness. Films of $3 \mathrm{WO}_{3} \cdot \mathrm{H}_{2} \mathrm{O}$ are colorless, so the transmission is lower for thicker films because of scattering, which is lower for

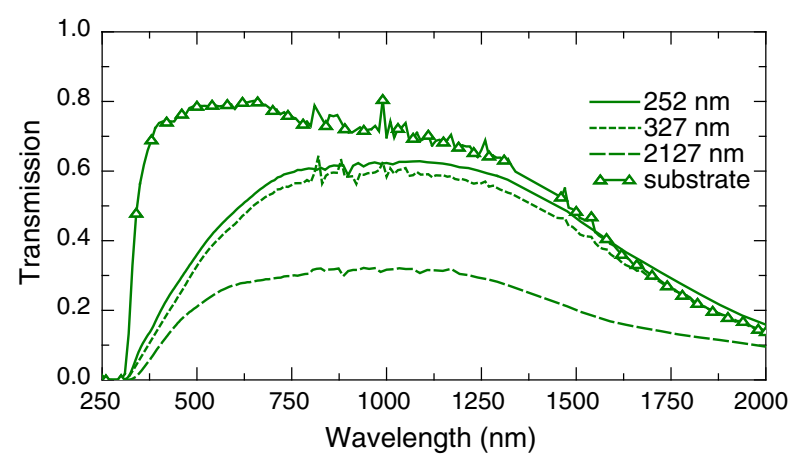

Fig. 2. Transmittance of $3 \mathrm{WO}_{3} \cdot \mathrm{H}_{2} \mathrm{O}$ films with thicknesses of 252,327 and $2127 \mathrm{~nm}$ deposited on glass with FTO. Transmittance of an FTO-glass substrate is shown for comparison. thinner films. This is in good agreement with the film morphology. SEM pictures indicate that nano-plates of $3 \mathrm{WO}_{3} \cdot \mathrm{H}_{2} \mathrm{O}$ are randomly distributed on the FTO-glass substrate and are larger for thicker $3 \mathrm{WO}_{3} \cdot \mathrm{H}_{2} \mathrm{O}$ films [5]. Due to large scattering of the samples, the ellipsometric characterization of $3 \mathrm{WO}_{3} \cdot \mathrm{H}_{2} \mathrm{O}$ films was done only in the infrared spectral region. Before the $3 \mathrm{WO}_{3} \cdot \mathrm{H}_{2} \mathrm{O}$ films were analyzed, ellipsometric characterization of the FTO layer was performed. Fig. 3 shows experimental and fitted model $\Psi$ and $\Delta$ data for an FTO layer on glass and the extracted dielectric function of the FTO layer.

As mentioned above, tungsten trioxide thin films have an orthorhombic crystal structure, which implies that they should have anisotropic optical properties. However, anisotropy was not detected by ellipsometric measurements, which most probably is due to the random distribution of the hydrate plates. Therefore the optical investigations were performed using an isotropic parametric model from which the film thicknesses 252, 327 and $2127 \mathrm{~nm}$ were extracted. Experimental and fitted model $\Psi$ and data $\Delta$ for the $3 \mathrm{WO}_{3} \cdot \mathrm{H}_{2} \mathrm{O}$ film with a thickness of $252 \mathrm{~nm}$ are shown in Fig. 4a as an example. The good agreement between the imaginary and real parts of the dielectric functions obtained from the parametric model and from a point-by-point fit is illustrated in Fig. $4 \mathrm{~b}-\mathrm{d}$ for the three films. This agreement also verifies the KKconsistency of the pbp-results. The imaginary part of dielectric functions
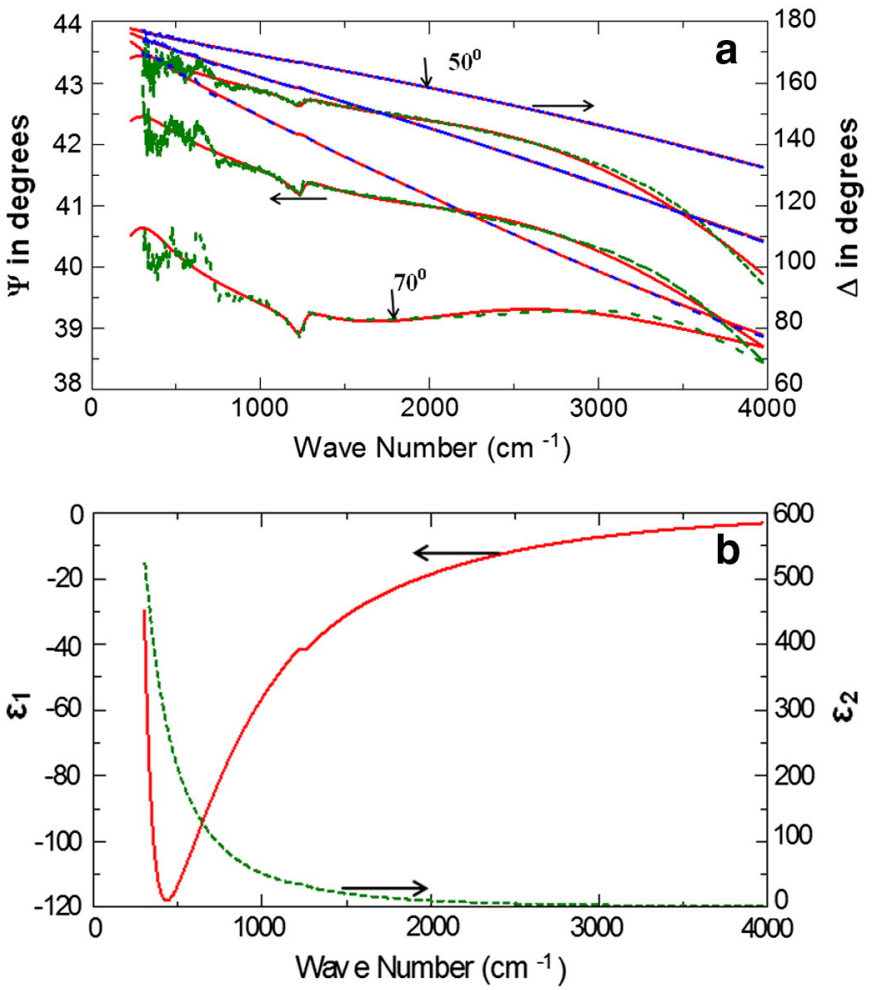

Fig. 3. (a) Experimental (dashed curves) and the best fits (solid lines) of the $\Psi$ and $\Delta$ spectra for an FTO film and (b) its dielectric function. 

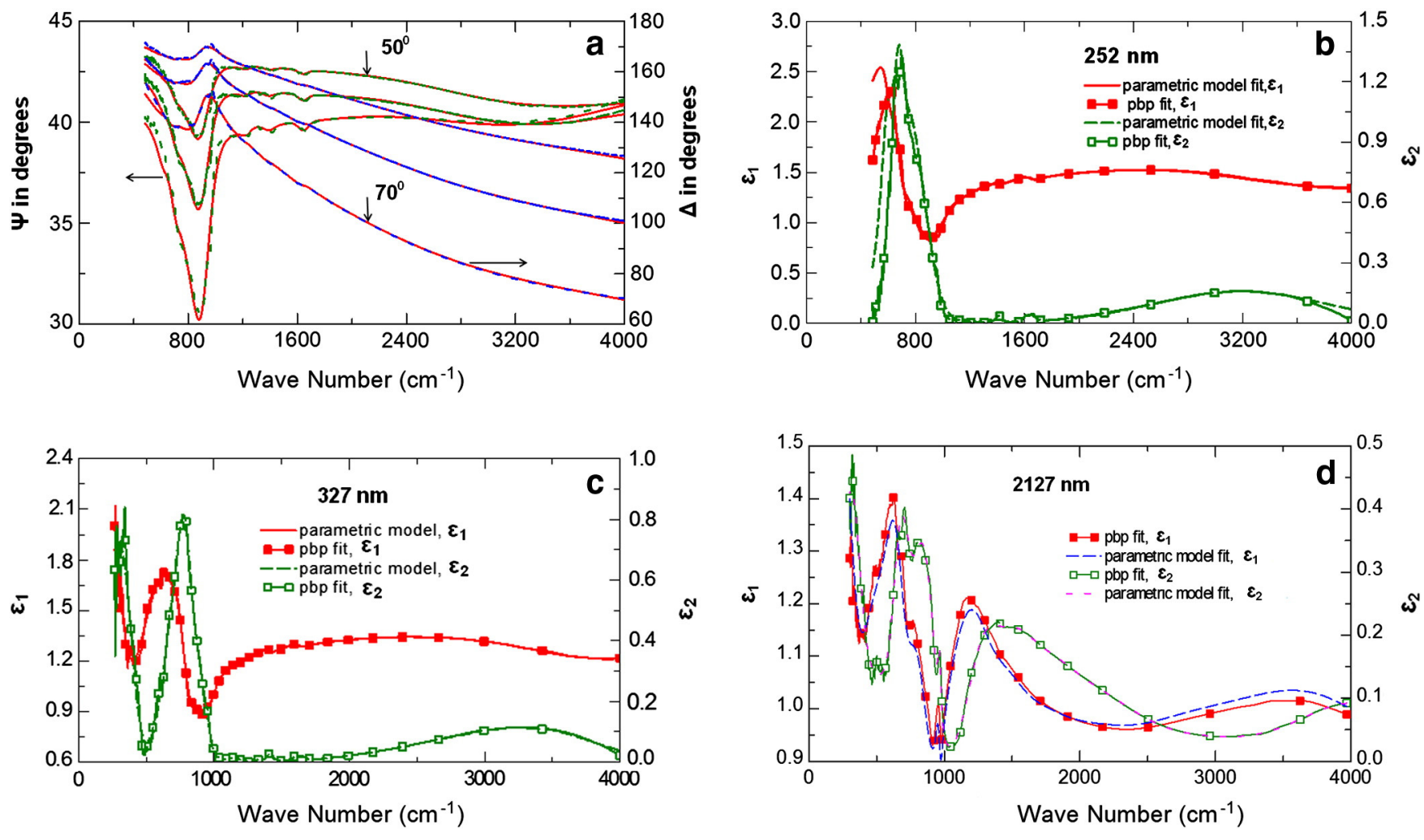

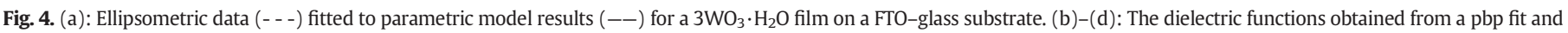
parametric model fit.

obtained by pbp fit for films with different thicknesses is presented in Fig. 5 for comparison.

For interpretation of the obtained results, we have compared them with earlier published IR spectra for $3 \mathrm{WO}_{3} \cdot \mathrm{H}_{2} \mathrm{O}$ and $\mathrm{WO}_{3}$ as well as $\mathrm{WO}_{3} \cdot \mathrm{H}_{2} \mathrm{O}$ and $1 / 2 \mathrm{WO}_{3} \cdot \mathrm{H}_{2} \mathrm{O}$ hydrates. Characteristic frequencies found in the $3 \mathrm{WO}_{3} \cdot \mathrm{H}_{2} \mathrm{O}$ films are presented in Table 1 . The bands at 701 and $653 \mathrm{~cm}^{-1}$ (Fig. 5) arise from $\mathrm{O}-\mathrm{W}-\mathrm{O}$ stretching vibrations $(\nu \mathrm{O}-\mathrm{W}-\mathrm{O}$ ) of the bridging oxygen atoms, whereas the bands at $1000,953,829$ and $779 \mathrm{~cm}^{-1}$ are due to the short terminal $\mathrm{W}=0$ bonds $(v \mathrm{~W}=0)$. The $\mathrm{W}-\mathrm{O}-\mathrm{W}$ stretching vibrations $(v \mathrm{~W}-\mathrm{O}-\mathrm{W})$ occur invariably in the $200-400 \mathrm{~cm}^{-1}$ region and are found at 354 , 338 and $327 \mathrm{~cm}^{-1}$. These results are, in general, in good agreement with earlier published IR spectra for $\mathrm{WO}_{3}$ and $3 \mathrm{WO}_{3} \cdot \mathrm{H}_{2} \mathrm{O}[2,3,7,12]$. However, some interesting differences should be noted. The band at $1410 \mathrm{~cm}^{-1}$ can be assigned to the $\mathrm{OH}$ bending modes $(\delta \mathrm{OH})$ that Daniel et al. [3] observed in the IR spectra of $3 \mathrm{WO}_{3} \cdot \mathrm{H}_{2} \mathrm{O}$, whereas a stretching $\mathrm{W}-\mathrm{OH}_{2}\left(v \mathrm{~W}-\mathrm{OH}_{2}\right)$ mode in the vicinity of $330 \mathrm{~cm}^{-1}$ (see Fig. 5 ) was also observed in the IR spectra of $1 / 2 \mathrm{WO}_{3} \cdot \mathrm{H}_{2} \mathrm{O}$ and $\mathrm{WO}_{3} \cdot \mathrm{H}_{2} \mathrm{O}$ [3]. However, the band at $600 \mathrm{~cm}^{-1}$ (Fig. 5) arising from $v 0-\mathrm{W}-\mathrm{O}$ indicates the presence of $1 / 2 \mathrm{WO}_{3} \cdot \mathrm{H}_{2} \mathrm{O}$ compounds in films $[3,4]$. Each $\mathrm{W}$ atom in the crystal structure of $1 / 2 \mathrm{WO}_{3} \cdot \mathrm{H}_{2} \mathrm{O}$ has one terminal oxygen, one coordinated water and four bridging oxygen atoms with which $\mathrm{WO}_{5}\left(\mathrm{H}_{2} \mathrm{O}\right)$ octahedra are connected with each other to form a neutral $\mathrm{WO}_{3}\left[\mathrm{H}_{2} \mathrm{O}\right]$ layer. The other water (structural water) is accommodated between such layers as interlayer crystal water [4]. The origin of the bands at 1151 and $1245 \mathrm{~cm}^{-1}$ is not clear, although the bands of bending vibrations of $\mathrm{W}-\mathrm{OH}$ have been observed in this spectral range [2].

From the obtained dispersions of dielectric functions in IR it can be concluded that the investigated films retain a great amount of water. Adsorbed water is indicated by a band in the vicinity of $1606 \mathrm{~cm}^{-1}$ and broad bands at 3208 and $3480 \mathrm{~cm}^{-1}$ for the two thinner films.
These bands can be assigned to bending $\left(\delta \mathrm{H}_{2} \mathrm{O}\right)$ and stretching $\left(v \mathrm{H}_{2} \mathrm{O}\right.$ ) modes of hydrogen bonded to the adsorbed OH-groups [7]. The bending mode in the vicinity of $1660 \mathrm{~cm}^{-1}$, which is observed for the film with a thickness of $252 \mathrm{~nm}$, is associated with the presence of the bulk water [13].

Large peaks at $\sim 1400$ and $\sim 1495 \mathrm{~cm}^{-1}$ are observed in the $\varepsilon_{2}$ spectrum for the film with a thickness of $2127 \mathrm{~nm}$. The thickest film seems to be more sensitive to absorbed water in comparison with the other, because absorption at $1606 \mathrm{~cm}^{-1}$ is much larger for this film. The origin of the peak shifting is not clear, but can be related to the presence of water molecules in the gas phase in the porous film.

The band in the vicinity of $494 \mathrm{~cm}^{-1}$ for the thickest film is observed in a spectral region where bands attributed to the "librational" motion of water molecules $[14,15]$ occur, i.e. bands appear due to a rotational motion of individual water molecules, which is restricted by hydrogen bonding to four surrounding water molecules.

\section{Conclusions}

IR spectroscopic ellipsometry was applied for characterization of orthorhombic $3 \mathrm{WO}_{3} \cdot \mathrm{H}_{2} \mathrm{O}$ films of different thicknesses. The thicknesses of the films and their dielectric functions have been extracted from experimental data using a parametric model as well as a pbp fit. The obtained dielectric functions are in good agreement with the earlier published IR spectra of $3 \mathrm{WO}_{3} \cdot \mathrm{H}_{2} \mathrm{O}[3,4,7,12]$ and the presence of $1 / 2 \mathrm{WO}_{3} \cdot \mathrm{H}_{2} \mathrm{O}$ compounds in the films is indicated. Moreover, it was proved that films retain a great amount of water, especially the film with a thickness of $2127 \mathrm{~nm}$. In addition, thicker films scatter more light due to the larger size of nano-plates. 

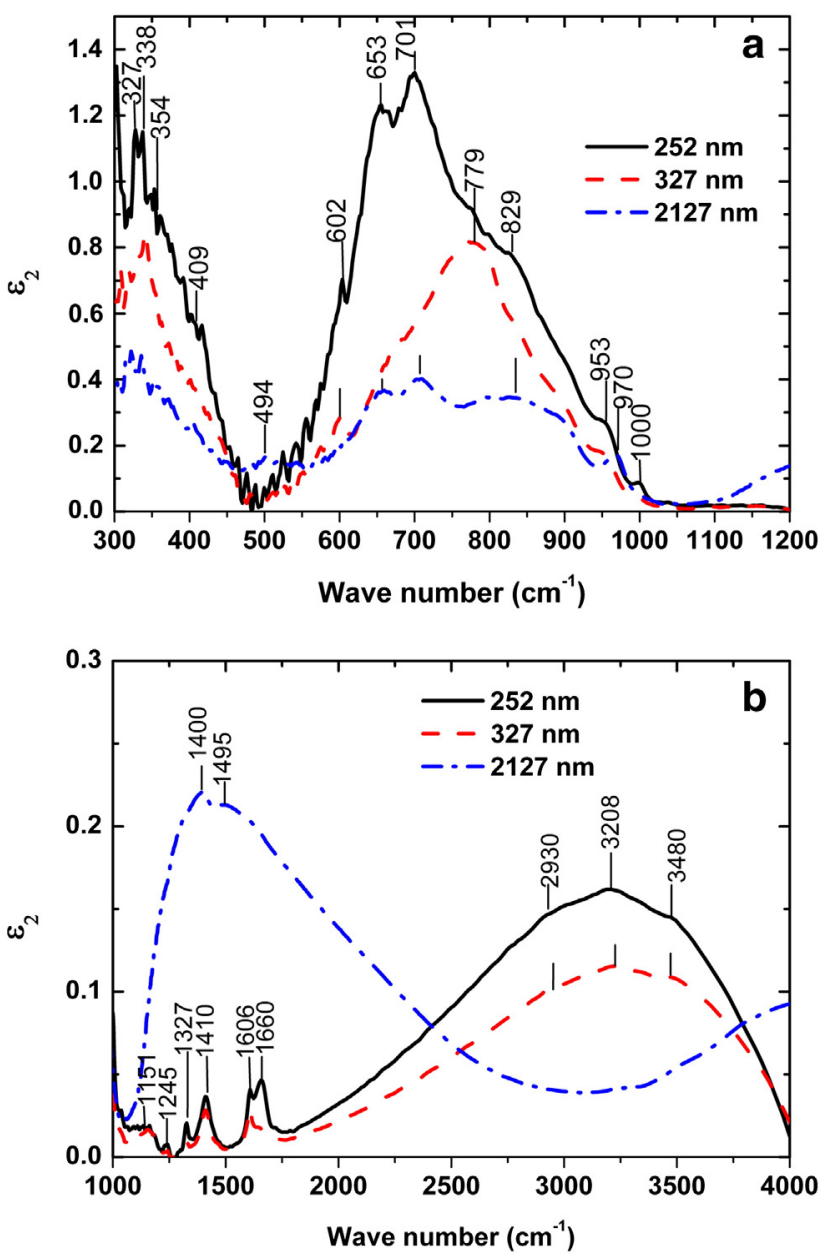

Fig. 5. (a) $\varepsilon_{2}$ of $3 \mathrm{WO}_{3} \cdot \mathrm{H}_{2} \mathrm{O}$ obtained by pbp fits in the spectral range $300-1200 \mathrm{~cm}^{-1}$ and (b) $1000-4000 \mathrm{~cm}^{-1}$.
Table 1

Characteristic frequencies $\left(\mathrm{cm}^{-1}\right)$ found in $3 \mathrm{WO}_{3} \cdot \mathrm{H}_{2} \mathrm{O}$ films.

\begin{tabular}{lcc}
\hline Attribution & $3 \mathrm{WO}_{3} \cdot \mathrm{H}_{2} \mathrm{O}$ & Reference [3] \\
\hline$v \mathrm{OH}$ & & 3550 \\
$\nu \mathrm{H}_{2} \mathrm{O}$ & 3480 & 3495 \\
& 3208 & 3220 \\
$\delta \mathrm{H}_{2} \mathrm{O}$ & 1606 & 1609 \\
$\delta \mathrm{OH}$ & 1410 & 1410 \\
$v \mathrm{~W}=\mathrm{O}$ & 1000 & 1000 \\
& 953 & 950 \\
& 829 & 820 \\
$v \mathrm{O}-\mathrm{W}-\mathrm{O}$ & 779 & 740 \\
& 701 & 710 \\
$v \mathrm{~W}-\mathrm{OH} \mathrm{H}_{2}$ & 653 & 660 \\
$v \mathrm{~W}-\mathrm{O}-\mathrm{W}$ & 409 & 425 \\
& 354 & 364 \\
& 338 & 338 \\
\hline
\end{tabular}

\section{Acknowledgments}

The Knut and Alice Wallenberg Foundation is acknowledged for financial support to instrumentation (Projects Nos. 2000 0130, 2004 0233).

\section{References}

[1] C.G. Granqvist, Handbook of Inorganic Electrochromic Materials, Elsevier, Amsterdam, The Netherlands, 1995.

[2] G.N. Kustova, Yu.A. Chesalov, L.M. Plyasova, I.Yu. Molina, A.I. Nizovskii, Vib. Spectrosc. 35 (2011) 235.

[3] M.F. Daniel, B. Desbat, J.C. Lassegues, J. Solid State Chem. 67 (1987) 235

[4] Y.M. Li, M. Hibino, M. Miyayaniya, T. Kudo, Solid State Ionics 134 (2000) 271.

[5] Z. Jiao, X. Wang, J. Wang, L. Ke, H.V. Demir, T.W. Koh, X.W. Sun, Chem. Comm. 48 (2012) 365.

[6] Z. Jiao, J. Wang, L. Ke, X. Liu, H.V. Demir, M.F. Yang, X.W. Sun, Electrochim. Acta 63 (2012) 153.

[7] M. Boukriba, F. Sediri, N. Gharbi, Polyhedron 29 (2010) 2070.

[8] C. Costa, C. Pinheiro, I. Henriques, C.A.T. Laia, Appl. Mater. Interfaces 4 (2012) 1330

[9] P.S. Partil, P.R. Partil, S.S. Kamble, S.H. Pawar, Sol. Energy Mater. Sol. Cells 60 (2000) 143.

[10] H.G. Tompkins, E.A. Irene (Eds.), Handbook of Ellipsometry, William Andrew Publishing, New York, USA, 2005.

[11] P.J.A. Woollam, Co., Inc., Guide to using WVASE32, WexTech Systems (2014).

[12] I. Valyukh, S.V. Green, C.G. Granqvist, G.A. Niklasson, S. Valyukh, H. Arwin, Thin Solid Films 519 (2011) 2914.

[13] M. Praprotnik, D. Janezic, J. Mavri, J. Phys. Chem. A 108 (2004) 11056.

[14] Y. Inada, H.H. Loeffler, Chem. Phys. Lett. 358 (2002) 449.

[15] I.M. Svishchev, P.G. Kusalik, J. Chem. Soc. Faraday Trans. 90 (1994) 1405. 